\title{
Platelet monoamine oxidase activity and headache
}

\author{
VIVETTE GLOVER,* R PEATFIELD, $\dagger$ ROSEMARY ZAMMIT-PACE,* JULIA \\ LITTLEWOOD,* M GAWEL, $\dagger$ F CLIFFORD ROSE, $\dagger$ M SANDLER*
}

From the *Bernhard Baron Memorial Research Laboratories and Institute of Obstetrics and Gynaecology, Queen Charlotte's Hospital, and the †Department of Neurology, Charing Cross Hospital Medical School, London

SUMMARY Mean platelet monoamine oxidase activity was reduced compared with control values in groups of headache-free male (but not female) patients suffering from classical migraine and from tension headache. Mean activity in male cluster patients, headache free, both during acute and quiescent phases of their illness, was also notably reduced. Retesting some migraine subjects after up to four years, showed that low activity may be a persistent feature: the correlation coefficient for repeated assays was $0.91(\mathrm{p}<0.01)$. There was no relationship between platelet monoamine oxidase activity and history of dietary migraine. A subgroup of headache patients with permanently low monoamine oxidase activity values may have been defined.

Monoamine oxidase (MAO) catalyses the oxidative deamination of a wide range of biologically active monoamines. The human platelet contains solely MAO B, ${ }^{1}$ the form of the enzyme which numbers among its substrate preferences phenylethylamine, ${ }^{2}$ and other less well-studied "trace amines"3 as well as tele-methylhistamine. ${ }^{4-6}$ This recently discovered role of MAO B in histamine metabolism is of interest as Hanington? reported in 1974 that particularly low platelet MAO activity had been observed in a single patient with cluster headache, an observation later confirmed by Bussone $e t a^{8}$ and histamine has been involved as a possible aetiological factor in the genesis of cluster headache. ${ }^{910}$

The evidence concerning platelet MAO activity in migraine is complex and conflicting, ${ }^{11-14}$ and two phenomena need to be distinguished. First there can be transient changes during a migraine attack as noted in our previous study. ${ }^{13}$ Secondly, there may be some individuals with permanently low MAO activity. Some publications have noted a significant reduction in mean platelet MAO activity in headachefree migraine patients ${ }^{11} 12$ but others have failed to confirm this finding. ${ }^{13} 14$

In this study, we have confined ourselves to the headache-free period and have carried out a further

Address for reprint requests: Professor Merton Sandler, Queen Charlotte's Maternity Hospital, Goldhawk Road, London W6 0XG, UK.

Accepted 13 July 1981 study on a larger number of patients. What may appear as a trend with small numbers can be established definitively with a larger sample. The patients were separated into groups, classified as common migraine, classical migraine, tension headache and cluster headache.

\section{Methods}

Test and control subjects were selected from patients and staff at the Princess Margaret Migraine Clinic, Charing Cross Hospital, and blood samples from them processed in parallel. Common and classical migraine were diagnosed according to the criteria of Vahlquist. ${ }^{15}$ Patients with intermittent headache without structural cause who did not fulfil any of Vahlquist's criteria were diagnosed as tension headache. The diagnosis of cluster headache was made using conventional criteria. ${ }^{1516}$ Patients in whom an unequivocal diagnosis could not be made were excluded from the study. For the second study of cluster headache, blood samples from a larger group of 35 male patients (cluster group 2) was obtained. To control for the possible effects of centrifugation, room temperature and storage time, blood from a new group of 30 male controls was processed in parallel with these (male control group 2). All the patients were free from headache at the time blood was taken: four out of six of the cluster group 1 patients were in or finishing a cluster period, as were all of the 35 cluster group 2 patients. Later 15 of these returned for retesting during a quiescent period. Their mean period since the last cluster was 4.5 months. We used a diagnosis of dietary migraine for patients who said that their headache could be triggered 
by cheese or chocolate (in almost all cases both) and excluded those whose history was inconclusive.

Venous blood $(10 \mathrm{ml})$ was added to $0.5 \mathrm{ml}$ of $5 \%(\mathrm{w} / \mathrm{v})$ $\mathrm{Na}_{2}$ EDTA in Universal containers. The sample was centrifuged at $320 \mathrm{~g}$ for $6 \mathrm{~min}$ and the platelet-rich plasma withdrawn and recentrifuged at $2,500 \mathrm{~g}$ for $15 \mathrm{~min}$. The platelet pellet was resuspended and washed in $1 \mathrm{ml}$ of $0.15 \mathrm{M} \mathrm{NaCl}$ and recentrifuged at $2,500 \mathrm{~g}$ for a further $15 \mathrm{~min}$. The pellet was resuspended in $1 \mathrm{ml}$ of $0 \cdot 15 \mathrm{M} \mathrm{NaCl}$ and stored at $-20^{\circ} \mathrm{C}$. MAO was assayed blind and in duplicate with ${ }^{14} \mathrm{C}$-tyramine as substrate at a final concentration of $150 \mu \mathrm{M}$. Protein was assayed by the method of Lowry et al. ${ }^{17}$ The results were expressed as nmoles of tyramine oxidised per $\mathrm{mg}$ protein in $30 \mathrm{~min}$. A further EDTA blood sample was sent for a routine platelet count.

On occasion we have encountered a low protein yield from platelets, particularly from headache subjects, and such a preparation possesses low specific MAO activity. On testing a subsequent sample from the same individual, normal platelet protein concentration is observed and MAO activity per unit protein also increases. We have, therefore, excluded all assay data where the amount of platelet protein recovered was less than $1.5 \mathrm{mg} / \mathrm{ml}$. The two-tailed Student's $t$ test was used for statistical analysis, unless otherwise stated.

\section{Results}

A total of 111 previously untested patients were studied. The results are shown in fig $1 \mathrm{a}$, b. In none of the different categories of female patient was mean MAO activity different from controls or from each other. Mean values \pm SE were: female controls $16 \cdot 7 \pm 1 \cdot 5$; classical migraine $15 \cdot 3 \pm 1 \cdot 4$; common migraine $16.6 \pm 0.9$; tension headache $15.9 \pm 1.6$ nmoles tyramine oxidised $/ \mathrm{mg}$ protein $/ 30 \mathrm{~min}$. The pattern for the males was different. Mean values $\pm \mathrm{SE}$ were: male controls $16 \cdot 3 \pm 1 \cdot 3$; classical migraine $10.9 \pm 0.9$; common migraine $13.9 \pm 1 \cdot 1$; tension headache $10 \cdot 7 \pm 1 \cdot 1$; cluster headache $9 \cdot 0 \pm 1 \cdot 3$ nmoles tyramine oxidised $/ \mathrm{mg}$ protein $/ 30 \mathrm{~min}$. Mean values in males with classical migraine and with tension headaches were lower than those of controls $(p<0.01)$ whilst activity in cluster headache was even lower $(p<0.002)$. Although some decrease in activity was present in males with common migraine, the difference was not significant. Cluster headache group 2 also showed low activity $(13.7 \pm 0.6 \mathrm{com}$ pared with $16.9 \pm 0 \cdot 8$ in a different group of male

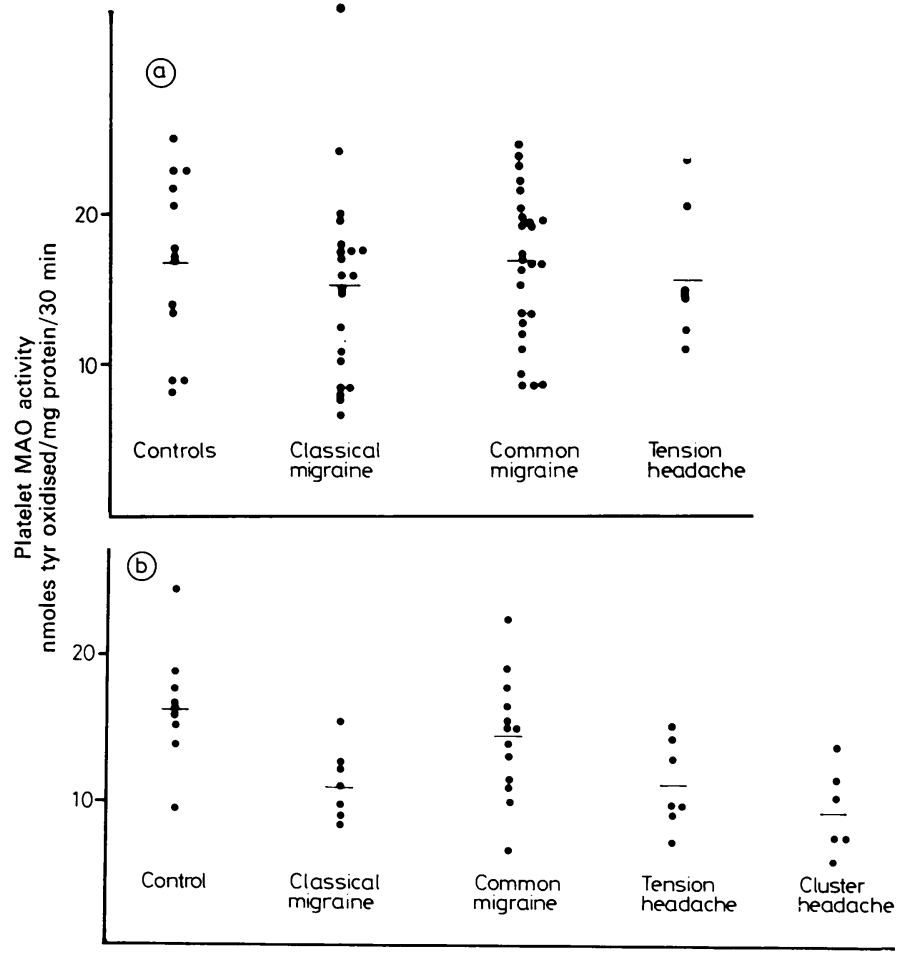

Fig $a$ and $b$

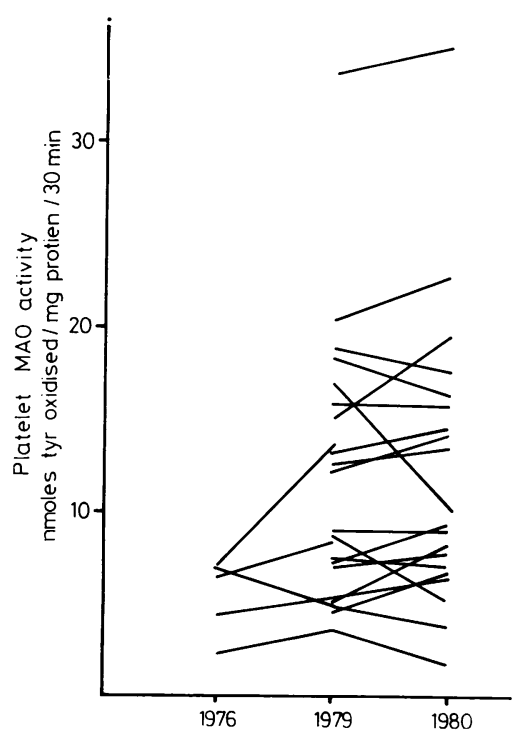

Fig c

Fig 1(a) Platelet MAO activity in female headache patients and female controls. (b) Platelet MAO activity in male headache patients and male controls. Both expressed as nmoles tyramine/oxidised/mg protein/30 min. (c) Repeated $M A O$ assays on the same individual. 
controls; $p<0.01)$. These patients were later retested while quiescent, showing a mean activity of $12 \cdot 8 \pm 1 \cdot 2$, also less than control group $2(p<0 \cdot 01$.

Only four men gave a history of dietary migraine. Of these, three had activities close to the mean male control value, and only one had low activity (more than $1 \mathrm{SD}$ below this). Other men with low activity had not noticed any association between dietary factors and their headaches. There was no difference in mean activity when women with common or classical migraine were divided into those with a history of headache in response to cheese or chocolate $(16.1 \pm 1 \cdot 3)$ and those without $(15.5 \pm 0.9)$. The range of activities in the two groups was also the same.

A small number of patients were taking different prophylactic drugs but these had little effect on the mean activities obtained. The male patients who were untreated had mean values that were below male controls in a similar way to the groups as a whole, as follows: classical migraine $(n=6)$ $11.3 \times 0.95, \mathrm{p}<0.02$; common migraine $(\mathrm{n}=10)$ $14 \cdot 2 \pm 1 \cdot 4$, NS; tension headache $(n=6) 11 \cdot 5 \pm 1 \cdot 1$, $\mathrm{p}<0.02$; cluster headache $(\mathrm{n}=5) 9.5 \pm 1.4$, $\mathrm{p}<0.01$.

In our previous study of platelet MAO activity in migraine, carried out in $1977,{ }^{13}$ we found that while most migraine patients had activity within the normal range, five showed values below those of the control group. These were all men, although the majority of the patients $(71 \%)$ were women; four had common migraine and one had classical migraine. We invited the five to be retested and four of them still had low activity, three on two subsequent occasions. One of these men had not had a headache for over one year. We have also retested several of our recently identified low activity migraine patients, together with some patients with higher activity and some controls. Figure 1c shows the results of these repeated assays on the same individual and the general stability of the MAO activity. The correlation coefficient for the group as a whole was $0.91(p<0.01)$.

Platelet protein concentration and platelet count were within the normal range in the different groups under investigation. The table shows the results of these measurements in males; mean values for each group were similar.

\section{Discussion}

We have found that mean platelet MAO activity between attacks in males with classical migraine, with tension headache and with cluster headache was lower than that of a control group and that this was a permanent feature of these individuals. Maleness has not previously been recorded as a significant contributory factor to low MAO activity in migraine, although in control populations it has frequently been observed that females have higher mean activity than males. ${ }^{18}$ It is not without interest that this particular biochemical finding is not confined to migraine but has been observed in a variety of different headache syndromes. There is a common belief that if the clinical diagnosis can be made with greater precision, the accompanying biochemical changes will become more reproducible from study to study. Rather than a different cause being responsible for each variant, which this approach presupposes, it seems just as likely that the origins of each are multifactorial, with different constellations of factors operating in different subgroups.

The only previous investigation of a group of $D$ cluster headache patients 8 also found low activities. ${ }^{\circ}$ o We have now studied this type of patient both during $\stackrel{\circ}{\circ}$ 응 the headache-free cluster period and during $\mathbb{\Phi} \rightarrow$ quiescence and found that the low MAO activity is a permanent feature.

We found no evidence to show that low MAO activity predisposes to dietary migraine but, even so are unable to rule out the association completely in individual patients. There remains the possibility that in a few cases, particularly low MAO activity does cause a sensitivity to amine-containing foods. Nor were we able to demonstrate any connection between activity and drug administration, confirming our earlier study. ${ }^{13}$

A recurring problem with studies of platelet MAO activity in both migraine ${ }^{19}$ and other diseases such as schizophrenia is an apparent lack of reproducibility. ${ }^{20}$ Although a reduction in platelet MAO activity in migraine patients outside an attack has been recorded in some studies, others, including our previous one, ${ }^{13}$ have failed to confirm it. A likely explanation for this is biochemical heterogeneity. An investigation that fails to demonstrate a difference

Table Platelet count and platelet protein in males (mean $\pm S E)$

\begin{tabular}{lcccc}
\hline & Control & $\begin{array}{l}\text { Classic } \\
\text { migraine }\end{array}$ & $\begin{array}{l}\text { Common } \\
\text { migraine }\end{array}$ & $\begin{array}{l}\text { Tension } \\
\text { headache } \\
\text { headache }\end{array}$ \\
\hline Platelet count $\times 10^{-3}$ & $209 \pm 12$ & $264 \pm 27$ & $245 \pm 9$ & $192 \pm 21$ \\
Platelet protein $(\mathrm{mg} / \mathrm{ml})$ & $2 \cdot 4 \pm 0 \cdot 2$ & $2 \cdot 6 \pm 0.4$ & $2 \cdot 9 \pm 0.2$ & $2 \cdot 7 \pm 0.1$ \\
\hline
\end{tabular}


between two small groups does not prove that they are the same. In this present study, we have found no difference in mean platelet MAO activity between males and females, although the evidence is very strong that females in general do have a higher mean activity than males. ${ }^{18}$ The way to overcome this problem is to investigate and analyse a sufficiently large number of patients and controls. The cumulative evidence now suggests that among male patients there are more individuals with low platelet MAO activity than among controls but the results of any particular study will depend on how many of these low activity individuals are included. In the present study, we have found a reduction in male classical but not common migraine patients, whereas the lowest values in our previous study ${ }^{13}$ came from the male common migraine group.

A central question remaining is whether a platelet MAO defect reflects an abnormal platelet population or an abnormality of the enzyme itself. Platelets from migrainous patients aggregate more readily, even when studied outside an attack ${ }^{21} 22$ and a number of accompanying changes have been noted during attacks including release of 5-hydroxytryptamine ${ }^{23}$ and $\beta$-thromboglobulin, ${ }^{24}$ and a decrease in specific MAO activity. ${ }^{13}$ We do not know whether these changes are specific to migraine or are associated with other headache syndromes. One possible explanation of the present findings would be that we have identified a subgroup of patients with abnormal platelets.

Platelets are heterogeneous and large dense platelets have a higher specific MAO activity than smaller lighter ones..$^{25}$ Our observation that specific MAO activity may depend on the amount of platelet protein recovered agrees with this, indicating that the larger more active platelets are lost in the preparation procedure when we have a low protein yield. This finding suggests that, in general, during studies of platelet function in migraine, care needs to be taken to ensure a representative yield of platelets. However, both mean platelet count and protein assay in all groups tested in this study were similar to control values. Thus it is quite possible that, at least in some individuals, low platelet enzyme activity reflects a similar change throughout the body; this change may even be a predisposing factor to headache. We now need techniques for gauging MAO activity in sites in the body other than the platelet and, more particularly, for making direct measurements of MAO A activity.

VG is supported by the Parkinson's Disease Society and RP and JL by the Migraine Trust.

\section{References}

${ }^{1}$ Donnelly $\mathrm{CH}$, Murphy DL. Substrate- and inhibitorrelated characteristics of human platelet monoamine oxidase. Biochem Pharmacol 1977;26:853-8.

2 Yang H-YT, Neff NH. $\beta$-Phenylethylamine: a specific substrate for type B monoamine oxidase. $J$ Pharmacol Exp Ther 1973;187:365-71.

${ }^{3}$ Usdin E, Sandler M. eds. Trace Amines and the Brain. New York: Dekker, 1976.

${ }^{4}$ Hough LB, Domino EF. tele-Methylhistamine oxidation by type-B monoamine oxidase. $J$ Pharmacol Exp Ther 1979;208:422-8.

5 Waldmeier PC, Feldtrauer J-J, Maitre L. Methylhistamine: evidence for selective deamination by MAO B in rat brain in vivo. $J$ Neurochem 1977; 29:786-90.

${ }^{6}$ Elsworth JD, Glover V, Sandler M. tele-Methylhistamine is a specific MAO B substrate in man. Psychopharmacology 1980;69:287-90.

' Hanington E. Monoamine oxidase and migraine. Lancet 1974 ;ii :1148-50.

${ }^{8}$ Bussone G, Giovannini P, Boiardi A, Boeri R. A study of the activity of platelet monoamine oxidase in patients with migraine headaches or with "cluster headaches". Eur Neurol 1977;15:157-62.

${ }^{9}$ Sjaastad O. Is histamine of significance in the pathogenesis of headache? In: Diamond S, Dalessio DJ, Graham JR, Medina JL, eds. Vasoactive Substances Relevant to Migraine. Springfield: CC Thomas, 1975:45-66.

${ }^{10}$ Lance JW. The Mechanism and Management of Headache, 3rd Ed. London: Butterworths, 1978.

${ }^{11}$ Sicuteri F, Buffoni F, Anselmi B, del Bianco PL. An enzyme (MAO) defect on the platelets in migraine. Res clin Stud Headache 1972;3:245-51.

12 Sandler M, Youdim MBH, Hanington E. A phenylethylamine oxidizing defect in migraine. Nature 1974;250:335-7.

${ }^{13}$ Glover V, Sandler M, Grant E, Clifford Rose F, Orton D, Wilkinson M, Stevens D. Transitory decrease in platelet monoamine oxidase activity during migraine attacks. Lancet 1977; i:391-3.

14 Thomas DV. Platelet monoamine oxidase activity in classical migraine. Paper presented at International Migraine Symposium, Florence 1980.

15 Vahlquist B. Migraine in children. Int Arch Allergy 1955; 7:348-55.

${ }^{16}$ Ekbom K. A clinical comparison of cluster headache and migraine. Acta Neurol Scand 1970;Suppl. 41: $1-48$.

${ }^{17}$ Lowry OH, Rosebrough NJ, Farr AL, Randall RJ. Protein measurement with the Folin phenol reagent. $J$ biol Chem 1951;193:265-75.

${ }^{18}$ Murphy DL, Wright C, Buchsbaum M, Nichols A, Costa HL, Wyatt RJ. Platelet and plasma amine oxidase activity in 680 normals: sex and age differences and stability over time. Biochem Med 1976; 16:254-65.

${ }^{19}$ Sandler M. Implications of the platelet monoamine oxidase deficit during migraine attacks. Res clin Stud Headache 1978;6:65-72. 
${ }^{20}$ Sandler M. Reveley M, Glover V. Human platelet monoamine oxidase activity in health and disease: a review. J Clin Path 1981;34:292-302.

21 Couch JR, Hassanein RS. Platelet aggregability in migraine. Neurology (Minneap) 1977;27:843-8.

${ }^{22}$ Deshmukh SV, Meyer JS. Cyclic changes in platelet dynamics and the pathogenesis and prophylaxis of migraine. Headache 1977;17:101-8.

${ }^{23}$ Anthony M, Hinterberger H, Lance JW. Plasma serotonin in migraine and stress. Arch Neurol 1976;16:
544-52.

${ }^{24}$ Gawel MJ, Burkitt M, Clifford Rose F. Platelet release reaction during migraine attacks. Headache 1979: 19:323-7.

${ }^{25}$ Friedhoff AJ, Miller JC, Karpatkin S. Heterogeneity of human platelets. VII. Platelet monoamine oxidase activity in normals and patients with autoimmune thrombocytopenic purpura and reactive thrombocytosis: its relationship to platelet protein density. Blood 1978;51:317-23. 